\title{
BRIEF REPORT Modification of Biological Parameters After Treatment With Recombinant Factor VIIa in a Patient With Thrombocytopathy due to Storage Pool Disease
}

\author{
L. Langendonck and I.M. Appel*
}

\begin{abstract}
Patients with thrombocytopathy due to storage pool disease mostly suffer from mild bleeding diathesis. However surgical interventions can lead to excess bleeding. We describe how treatment with recombinant factor VIIa (Novoseven ${ }^{\mathbb{R}}$ ) during a surgical procedure in a
\end{abstract}

boy with SPD leads to an immediate rise in PF-4, thereby activating factor $\mathrm{Xa}$ on the platelet surface, leading to active thrombin generation. Pediatr Blood Cancer 2005;44:676-678.

(C) 2005 Wiley-Liss, Inc.

Key words: biological parameters; rVIla treatment; storage pool disease
Storage pool deficiencies (SPD) are a heterogenious group of segregation abnormalities [1]. Distinct forms are known such as gray platelet syndrome (GPS), $\delta$-SPD, and $\alpha \delta$-SPD where platelets lack $\alpha$-granules, dense bodies, or both to a variable degree [2]. The $\alpha$-granules contain substances like von Willebrand factor, fibronectine, and platelet factor 4 (PF4) which are necessary for cell contact, thrombin generation, and subsequent development of platelet aggregates. Absence of $\alpha$-granules in GPS, for example, can be monitored by PF4 deficiency. The dense bodies are a metabolically inert storage pool containing ATP, ADP, serotonine, calcium, and pyrophosphate, all of which are secreted in response to platelet activation. In $\delta$-SPD, the lowered amount of ADP leads to a diagnostic raised ATP/ADP ratio. Patients suffering from $\delta$-SPD present with easy bruising, petechiae, epistaxis, menorrhagia, and particularly postoperative and posttraumatic bleeding. Treatment is usually symptomatic; most patients respond to DDAVP, transfusions of platelet concentrates are the most appropriate approach in excess bleeding. However, with recurrent transfusions the risk of alloimmunisation exists, leading to a refractory state.

An alternative treatment for patients with a thrombocytopathy is recombinant factor VIIa (rFVIIa). The exact mechanism of the beneficial effect of rVIIa is not fully understood. Direct activation of small amounts of F Xa by rVIIa might lead to thrombin generation on the platelet surface itself compensating for the dysfunctionality of the platelets [3].

FVIIa has been successfully used in a few patients with Glanzmann Trombasthenia [4] and Bernard-Soulier syndrome [5], as well as in patients with thrombocytopenia [6]. To the best of our knowledge, the use of rFVIIa was described only once in an in vitro study of a case with SPD [7] and recently in a clinical study by Almeida [8].

We report a patient with a storage pool disease who successfully underwent dental surgery during treatment with rFVIIa.

A young male patient 13 years old, born from nonconsanguin Caucasian was diagnosed with $\delta$-SPD. He had a prolonged bleeding time of $8-13 \mathrm{~min}$ and a normal platelet count $\left(170-220 \times 10^{9} / \mathrm{L}\right)$. General haemostatis analyses concerning APTT, PT, thrombin time, and fibrinogen revealed values within the normal range. Platelet membrane glycoprotein complexes showed normal expression, but the patient had an elevated ATP/ ADP ratio of 5.5 measured in ethanol extracts with the luciferin-luciferase assay. The dental surgeon advised the extraction of three dental elements. After informed consent we decided to analyze the effect of rFVIIa treatment on SPD. During and $24 \mathrm{hr}$ after this procedure the patient was prophylactically treated with rFVIIa (NovoSeven ${ }^{\circledR}$, Novo Nordisk, Copenhagen, Denmark) and the anti-fibrinolytic agent tranexamic acid (Cyclokapron ${ }^{\circledR}$,

Department of Pediatrics, Division of Oncology-Hematology, Sophia Children's Hospital, University Hospital Rotterdam, Rotterdam, The Netherlands

*Correspondence to: I.M. Appel, Department of Pediatrics, Division of Oncology-Hematology, Sophia Children's Hospital, University Hospital Rotterdam, P.O. Box 2060, 3000 CB Rotterdam, The Netherlands. E-mail: i.m.appel@erasmusmc.nl

Received 19 April 2004; Accepted 19 July 2004 
TABLE I. Biological Parameters Before $(\mathrm{T}=-\mathbf{2 4} \mathrm{hr}$ ) and During (T0-T24) Treatment With rFVIIa in a Patient With Storage Pool Disease

\begin{tabular}{lccccccc}
\hline Time $(\mathrm{hr})$ & $\begin{array}{c}\text { Factor VII } \\
(\mathrm{IU} / \mathrm{ml})\end{array}$ & $\begin{array}{c}\mathrm{F}_{1+2} \\
(\mathrm{nmol} / \mathrm{L})\end{array}$ & $\begin{array}{c}\text { TAT } \\
(\mu \mathrm{g} / \mathrm{L})\end{array}$ & TAFI $(\%)$ & $\begin{array}{c}\text { D-dimer } \\
(\mu \mathrm{g} / \mathrm{L})\end{array}$ & $\begin{array}{c}\text { PF4 } \\
(\mathrm{IU} / \mathrm{ml})\end{array}$ & $\mathrm{BT}(\mathrm{min})$ \\
\hline-24 & 0.97 & 0.53 & 1.90 & 112 & 336 & $\mathrm{Nd}$ & 8.00 \\
0 & 0.95 & 0.52 & 2.40 & 117 & 200 & 10 & 7.50 \\
0.25 & 54.40 & 3.40 & 79.90 & 132 & 217 & 1711 & 6.50 \\
1 & 41.20 & 1.71 & 63.00 & 117 & 189 & 56 & 5.25 \\
5 & 25.70 & 3.41 & 74.10 & 82 & 265 & 199 & 3.15 \\
24 & 12.80 & 6.08 & 50.20 & 113 & 497 & 64 & 5.25 \\
Normal range & $0.9-1.1$ & $0.4-1.1$ & $1.0-4.1$ & $60-138$ & $<500$ & $0-5$ & $<5$ \\
\hline
\end{tabular}

Pharmacia\&Upjohn, Capella aan den ijssel, The Netherlands), four times daily. At $\mathrm{T}=0$ the patient received a bolus of rFVIIa $(100 \mu \mathrm{g} / \mathrm{kg})$ directly followed by a continuous infusion of $16 \mu \mathrm{g} / \mathrm{kg} / \mathrm{hr}$. During infusion, the bleeding time and levels of factor VIIa, prothrombin fragment $_{1+2}\left(\mathrm{~F}_{1+2}\right)$, TAT (Thrombin Antithrombin III complex), D dimer, PF4, and Thrombin Activatable Fibrinolysis Inhibitor (TAFI) were monitored. They were checked after $15 \mathrm{~min}(\mathrm{~T}=0.25), 1 \mathrm{hr}(\mathrm{T}=1), 5 \mathrm{hr}(\mathrm{T}=5)$, and $24 \mathrm{hr}(\mathrm{T}=24)$ (Table I). The infusion rate was calculated depending on the plasma factor VII level, intended to reach plasma levels of 6-20 IU $/ \mathrm{ml}$. The operation was performed at $\mathrm{T}=4$. Blood samples were collected in tubes containing 3.8\% trisodium citrate for the routine coagulation assays and in CTAD (citrate, theophylline, adenosine, dipyridamole) tubes for D-dimer and PF4 analysis. Samples were chilled immediately in an ice bath, centrifuged at $47.800 \mathrm{~g}$ for $30 \mathrm{~min}$ at $4^{\circ} \mathrm{C}$ and stored in $-80^{\circ} \mathrm{C}$.

Bleeding time was measured according to Ivy. Factor VII clotting activity was analyzed using a one step clotting activity method containing factor VII deficient plasma. $\mathrm{F}_{1+2}$ was measured using a commercial solid phase enzyme linked immunosorbent assay (Enzygnost $\mathrm{F}_{1+2}$, Behringwerke AG). TAT was determined with a commercial solid phase enzyme linked immuosorbent assay (Enzygnost TAT, Behringwerke AG, Marburg, Germany). D-dimer was also measured with a sandwich assay (Asserachrom ${ }^{\circledR} \mathrm{D}$-dimer) for the quantitative determination of fibrin degradation products. PF4 was quantitatively determined with an enzyme immunoassay (Asserachrom PF4). TAFI was measured with an enzyme linked immunosorbent assay.

The increased levels of FVIIa gradually lead to a normalization of the bleeding time. Increased thrombin generation is demonstrated by high levels of both TAT and $\mathrm{F}_{1+2}$ immediately after administration of rFVIIa. The normal plasma levels of $\mathrm{D}$-dimer suggests no degradation of fibrin or fibrinogen; normal measured levels of TAFI do not point to downregulation of fibrinolysis. An increase in PF4 immediately after the bolus injection of rFVIIa indicates the induction of platelet aggregation.
The use of recombinant factor VIIa in this patient with a storage pool disease leads to a normal hemostasis during and after the extraction of three dental elements. The underlying mechanisms by which the use of rFVIIa results in normal hemostasis in a patient with storage pool disease remain to be determined, but two possibilities are evident: a mechanism of enhanced thrombin generation or of inhibited fibrinolysis.

Enhanced thrombin generation is reflected by elevation of $\mathrm{F}_{1+2}$ and by the release of TAT. Considering the half lifes of $F_{1+2}$ and TAT being, respectively, 90 and $3 \mathrm{~min}$, thrombin generation seems an important process directly following the administration of rFVIIa. As expected, the rFVIIa infusion induces thrombin generation by activating the extrinsic pathway in a tissue-factor dependent manner. FVIIa reaches the expected elevated levels. The immediate rise in TAT and $\mathrm{F}_{1+2}$ appears already before any surgical event has taken place. This suggests immediate activation of thrombin generation not by the release of tissue factor but possibly by a tissue factor-independent pathway. Activation of small amounts of $\mathrm{F} X \mathrm{Xa}$ in the proximity to platelet surfaces can lead to an explosion of thrombin generation [3,9]. In our patient, we assume that rFVIIa binds to activated platelets activating Xa, generated on the platelet surface, hence leading to formation of the prothrombinase complex. As is demonstrated in the table the bolus injection of rFVIIa indeed leads to an immediate rise in PF-4 values. This may result in active aggregation of platelets by the brief release of a high amount of alpha-granule-specific PF-4, finally leading to the explosion of thrombin generation as mentioned above.

TAFI demonstrates no significant changes. High concentrations of thrombin seem to be necessary for the activation of TAFI [10]. Downregulation of fibrinolysis by TAFI activation has been demonstrated in in vitro studies to be an important factor in clot stabilization [11]. Until now this effect has not been monitored in in vivo situations.

In this patient with SPD, infusion of rFVIIa does not lead to a change in D-dimers nor to a rise in TAFI in a state of active thrombin generation. 
In conclusion, this patient with SPD demonstrates an increased thrombin generation possibly enhanced by triggering of the extrinsic pathway by rFVIIa. Increased levels of thrombin at the site of injury due to the operation might induce platelet aggregation. On the other hand, a tissue factor-independent activation of FXa occurs probably by the binding of rFVIIa to platelet surfaces, leading to an immediate burst of thrombin generation. This is demonstrated by elevated levels of PF-4 and the rise of TAT and $\mathrm{F}_{1+2}$, immediately after the infusion of rFVIIa even before surgical damage to the tissues.

Recombinant FVIIa demonstrates to be a safe alternative to platelet transfusions during surgical interventions in a patient with SPD. No adverse effects were observed.

\section{ACKNOWLEDGMENT}

We thank Ton Lisman from the University Medical Center Utrecht, The Netherlands, who measured TAFI for us.

\section{REFERENCES}

1. Bick RL. Platelet function defects: A clinical review. Semin Thromb Hemost 1992;18:167.
2. White JG. Platelet granule disorders. Crit Rev Oncol Hematol 1986;4:337.

3. Hoffman M, Monroe DM, Oliver JA, et al. Factors IXa and Xa play distinct roles in tissue-factor dependent initiation of coagulation. Blood 1995;86:1794-1801.

4. Poon MC, Demers C, Jobin F, et al. rFVIIa is effective for bleeding and surgery in patients with Glanzmann thrombasthenia. Blood 1999;94:3951.

5. Peters M, Heijboer H. Treatment of a patient with Bernard-Soulier syndrome and recurrent nosebleeds with recombinant factor VIIa. Thromb Haemost 1998;80:352.

6. Kristensen J, Killander A, Hippe E, et al. Clinical experience with rFVIIa in patients with thrombocytopenia. Haemostasis 1996;260: 159.

7. Lisman T, de Groot PG, Nieuwenhuis K. rFVIIa shortens the bleeding time in storage pool deficiency and improves in vitro and ex vivo platelet-aggregate formation under flow conditions. Thromb Haemost 1999;82:2354. (Abstract).

8. Almeida AT, Khair K, Hann I, et al. The use of recombinant factor VIIa in children with inherited platelet function disorders. Br J Haematol 2003;121:477-481.

9. Lisman T, Moschatsis S, Adelmeijer J, et al. Recombinant factor VIIa enhances deposition of platelets with congenital or acquiered alpha IIb beta 3 deficiency to endothelial cell matrix and collagen under conditions of flow via tissue factor-independent thrombin generation. Blood 2003;101:1864-1870.

10. Van Tilburg N, Rosendaal FR, Bertina RM. Thrombin activatable fibrinolysis inhibitor and the risk for deep vein thrombosis. Blood 2000;95:2855-2859.

11. Lisman T, Mosnier LO, Lambert T, et al. Inhibition of fibrinolysis by recombinant factor VIIa in plasma from patients with severe hemophilia A. Blood 2002;99:175. 